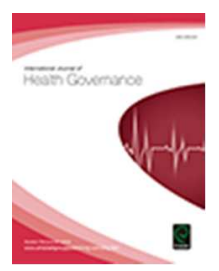

\title{
Reaching women with perinatal mental illness at the booking-in appointment
}

\begin{tabular}{|r|l|}
\hline Journal: & International Journal of Health Governance \\
\hline Manuscript ID & ijhg-08-2017-0044 \\
\hline Manuscript Type: & Original Article \\
\hline Keywords: & $\begin{array}{l}\text { Midwifery < Health Professions, Maternal \& child health, Behavioral, social } \\
\text { or mental health issues < Non-infectious conditions epidemiology, } \\
\text { Surveillance or screening < Public health, Health care quality < Health } \\
\text { Service Quality Assurance, Effectiveness < Health Service Quality } \\
\text { Assurance }\end{array}$ \\
\hline \hline
\end{tabular}

SCHOLARONE $^{\text {m }}$

Manuscripts 


\title{
Reaching women with perinatal mental illness
}

\author{
at the booking-in appointment
}

\begin{abstract}
At present the existing booking-in process, as regards to highlighting and diagnosing susceptibility to mental health conditions, has limited suitability. There is a possible future positive gain from early detection of mental ill health at this antenatal stage. The booking-in appointment offers a unique opportunity, early in pregnancy that could be more widely used as a point of detection, awareness and prevention of illness in the perinatal period. A more robust section of this appointment that includes both focused awareness of prior and current mental health concerns as well as the stigma attached to these conditions would be helpful for women. This may help to provide a much earlier detection of such conditions, allowing women to get much needed treatment prior to delivery. Later detection has inherent difficulties due to the huge pressures on women occurring naturally in the postnatal period, when time becomes a luxury that many women simply do not have. Also, the costs to the mother, the baby, the family and the economic costs to society, are considerable and an early, integrated detection and care system can help to ameliorate these costs. The postnatal period may not be the most timely and cost effective period for treatment and for some women this may be too late for them, with the harm already done to themselves, their baby and their family. There is a necessity for
\end{abstract}


research to assess the efficacy of such a strategy. This would need to include the cost to train the midwives to deliver this additional service, and the consideration of suitable treatment options at the antenatal stage using in-depth psychotherapy. There is research evidence to show that women in the perinatal period would prefer psychological therapy rather than psychotropic medication due to concerns for the welfare of their baby. The concerns women have regarding medication at this point in the perinatal period need to be upheld and listened to. This may help to reduce the high levels of attrition within treatment programmes currently running.

\section{Introduction}

Many women suffer from mental health conditions in either the antenatal or postnatal period. Until recently, such conditions were thought to occur mostly in the postnatal period. However, there is now a greater recognition that mental illness can often begin in pregnancy, with many women suffering from some sort of mental health issue in the antenatal period (Glover \& O'Connor, 2002). Postnatal depression is described by the medical profession as one of the most common forms of mental health conditions, and indeed complications of childbirth (Robertson, Celasun \& Stewart, 2003). Perinatal mental health is recognised by the World Health Organization as a major public health issue (Rahman et al., 2013; WHO, 2008), and it still remains a leading cause of maternal death in pregnancy and the first year after birth (MBRRACE - UK, 2016). There are also many women who enter pregnancy with a pre-existing mental health diagnosis, and around half of these women will relapse at some 
point within the perinatal period (Cohen et al., 2006). This number is likely to increase if these women choose to discontinue their medication during their pregnancy and post birth (Viguera et al., 2000).

It is known that depression in pregnancy is one of the strongest predictors of postnatal depression (Milgrom et al, 2008; O’Hara \& Swain, 1996). However, the scope of mental health issues is poorly recognised at the antenatal stage. There has been a great deal of research into what is termed medically as postnatal depression, with the Cochrane Database of Systematic Reviews estimating that this specific mental health condition affects between $10 \%$ and $15 \%$ of women in the UK (Dennis and Hodnett, 2007). Yet statistics for anxiety and stress in the perinatal period are virtually non-existent. Rubertsson et al found that $15 \%$ of women report anxiety in the antenatal period (Rubertsson et al., 2014). Two separate studies by Faisal-Curry and Menzes, and also Britton state the figure to be $24-45 \%$ over the entire perinatal period (Britton, 2008; Faisal-Curry \& Menzes, 2007). These statistics may be misleading as they only encompass women who have sought medical help for their condition. It is known that many women do not seek medical help, due to the stigma they perceive, and also due to fear that they might be judged as a poor mother and therefore be at risk of losing their baby.

Yet the consequences of perinatal mental health are great and can cause long term effects on the mother (Glover \& O'Connor, 2002), and infant (Agnafors et al., 2013; Deave et al., 2008; Field et al., 2010; Glover, 2014), with an increased likelihood of the child developing depression at some point in their life (Lester et 
al., 2013, p.556). Other consequences are complications such as low birth weight and preterm birth (Copper et al., 1996; Drewett et al, 2004; Field et al., 2004; Orr, James \& Blackmore, 2002; Rahman et al, 2004), impaired cognitive development, symptoms of attention deficit hyperactivity disorder and emotional problems (Conroy et al., 2012; Glover, 2014; Kingston \& Tough, 2014; Waters et al., 2014;), impaired maternal-foetal attachment (Lindgren, 2001), mother-infant interactions (Pearson et al., 2012) as well as trans-generational changes (Kaplan et al., 2013). There are considerable costs to the family affected, as well as economic consequences to society at large with recent research attributing around $£ 6.6$ billion per annum in economic costs to the United Kingdom (Bauer, et al., 2016). Research on intervention strategies is therefore needed, as well as the most appropriate and cost-effective time point for suitable intervention.

Several studies have also shown that women at most risk of mental illness during the perinatal period are those with a history of previous psychiatric illness (Coble et al., 1994; Kendell, Chalmers, \& Platz, 1987; Leight et al., 2010). It is possible that women who have suffered some kind of mental health issue, such as depression, stress and/or anxiety prior to their pregnancy, as well as some kind of life trauma, may well be at risk of mental ill health during the perinatal period. More research needs to be done to ascertain direct causal factors, and whether prior history does in fact lead to perinatal mental health as well as the percentages of risk involved. 


\section{Identifying Women at Risk}

Identifying women at risk, however, seems to be posing a difficulty in the medical profession. Research shows that as many as half of all cases of perinatal depression and anxiety may well be overlooked or unrecognised in the medical profession and left untreated (Bonari et al., 2004; Glover, 2014, p25). Midwives can play a really important part in identifying and referring women with mental health issues in pregnancy and the puerperium, although they may need more in-depth training for this than exists at present within their standard training. Midwives are the most likely medical professionals to have the greatest contact with women during pregnancy and immediately post birth. It is midwives who perform the booking-in appointment and they are in a unique position to both recognise the symptoms and to sign-post women for treatment during the earlier stages of pregnancy. However, to do this effectively they need more support. In a survey of midwives, $68 \%$ felt ill-equipped to identify and detect perinatal mental illness (Ross-Davie et al., 2006). Yet $90 \%$ of midwives said that psychological care was a core part of their public health role (Ross-Davie et al., 2006). Midwives receive little education on caring for women with mental health problems (McCauley et al, 2011) and as such have reported feeling unconfident in assessing such women and referring them on (Phillips \& Thomas, 2015). In a recent article (Noonan et al, 2017) midwives stated their knowledge on depression and anxiety as higher than severe mental health problems such as bipolar disorder, post-traumatic stress disorder and schizophrenia (Buist et al, 2006; Hauck et al., 2015; Jones et al, 2011). The same research concluded that limited knowledge and skills base, as well as a lack of referral options and the 
requirements of on-going educational and organisational support led to contraints in the care that midwives can give in perinatal mental health (Noonan et al., 2017).

Added to this there is also evidence that few women seek treatment in the antenatal period. In particular, Andersson et al state statistics as low as $5 \%$ of pregnant women with a mental health disorder undergoing psychopharmacological or psychotherapeutic treatment (Andersson et al., 2003). This may be due to symptoms being misinterpreted by midwives and doctors and it may be due to a lack of treatment possibilities considered safe for mother and fetus, as well as competing medical demands of work, family commitments and fatigue, for example (Vesga-Lopez et al., 2008). Those women who fall into the 'vulnerable' category, such as those who might have a personal or familial history of bipolar affective disorder, schizophrenia, or severe depression are most likely to be already known to the medical profession as a whole due to their past history. However, what about those other women, who may have suffered some mental health issue at some point in time during their history, and may have chosen not to seek help due to stigma or silencing. Those women are susceptible to becoming ill in the perinatal period. Yet would fall under the medical radar and remain unrecognised.

In England and Wales NICE recommend the extended Whooley questions (Whooley et al., 1997) to be used at booking-in to identify women at risk. However, there is concern that these are not sufficiently sensitive or provide a positive predictive value to be used as an assessment tool (Topiwala et al., 2012). 
NICE also advise the additional use of the Arroll 'help' question (Arroll et al., 2003) in order to incorporate a more self-selecting process for women who are initially identified using the Whoolley questions. However, research by Darwin et al., found documentation of routine mental health assessments at the bookingin appointment was inconsistent, with little monitoring of a woman's symptoms even when identified as at risk at this point (Darwin et al., 2014). These researchers believe their findings reflect a gap between 'best practice' and 'actual practice' (e21) and stress that women with mild to moderate symptoms in their research were not deemed unwell enough to receive specialist care. They also cited "mismanagement of mental health needs, and both poor communication with patients and between health professionals" (e21) as well as "mental health assessment (being) introduced without adequate resources for consistently responding to those women whose needs were identified" (e22) (Darwin et al., 2014). Further research by the team in 2016 found that the Whooley questions were not as accurate as the EPDS in identifying women with depression, the Whoolley questions failing to diagnose half of the possible cases of depression identified by the EPDS. Their research also discovered that reliance on the Arroll 'help' item may be misguided as in their research this question missed nine in ten possible cases identified using the EPDS (Darwin et al., 2016).

Qualitative research into the experiences of those women previously diagnosed with a mental illness at the booking-in stage also showed a lack of specialist knowledge around mental health disorders within midwifery, that would be facilitated by adequate training (Phillips \& Thomas, 2015). This research also 
highlighted a lack in the knowledge and skillset of GP's around mental health, and in particular perinatal mental illness and its impact on pregnancy and childbirth (p756). Clearly there would seem to be a gap both in knowledge within the medical profession, particularly within the professions who are directly in contact with women throughout their pregnancy and during the postnatal period. If conservative estimates stand at $10-15 \%$ of all women suffering from depression in the postnatal period alone, there would seem to be an absolute need for all midwives and doctors to have a good, clear knowledge of perinatal mental health conditions and care pathways for these women to access appropriate care.

\section{Appropriate Care Pathways}

There would seem to be a gap in funding for appropriate care pathways, particularly in the UK. If the annual cost to the UK economy of perinatal anxiety and depression is in the billions, it would seem appropriate to identify women at the earliest stage possible and put in place suitable treatment options, with the expectation of reducing the longevity of the condition and reducing the cost to the economy. More importantly for the women involved, the reduction in mental ill health and all that this would bring for the infant and family involved, as well as for the woman herself, the benefits may be substantial.

In 2008, in recognition of the high rate of maternal suicide, Australia implemented the National Perinatal Depression Plan (NPDP) (Australian Government Department of Health and Ageing, 2008) to form a cohesive, 
influential and wide-ranging response to perinatal anxiety and depression nationwide. This plan has wide-ranging goals including a more robust and comprehensive system of psychosocial assessment of women, education and training programme of health professionals and finally a robust system of care pathways to provide follow-up support and treatment for those women diagnosed with perinatal mental health difficulties.

Research also shows that psychotherapy would be a more preferable treatment option for women during pregnancy and in particular whilst breastfeeding, due to the lack of risk which is involved in medication (Fitelsen et al., 2011; Kim et al., 2011; Pearlstein et al., 2006). It is also a widely researched type of therapy for adult mental health, in particular depression, with effective results. It is a possible treatment strategy that may fill the gap recognised during the survey carried out by the National Society of Prevention of Cruelty to Children (NSPCC). This piece of research identified that in the UK, 64\% of Primary Care Trusts do not have a perinatal mental health strategy, and $73 \%$ of NHS maternity services do not have a specialist mental health midwife. It also discovered that $50 \%$ of Mental Health Trusts do not have a perinatal mental health service with a specialist psychiatrist (Hogg, 2013).

\section{Where next?}

At present, the future for women in the perinatal period with mental health conditions looks bleak. In 2016 the previous Prime Minister, David Cameron, 
pledged $£ 290$ million to help new and expectant mums with poor mental health (Gov. UK,

2016). This does not seem to have materialised to any great extent, as yet, probably due to him stepping down shortly afterwards. It would appear that there continues to be a lack of awareness and care for perinatal mental health, shown by the recent report 'Every mother must get the help they need' by the Royal College of Midwives (RCM, 2017). This report came from the detailed analysis of the comments from the Change.org petition, set up by Lucie Holland, after her sister's suicide due to perinatal mental ill health. Lucie Holland wanted to highlight the urgent need for better awareness and care within perinatal mental health. Within this research there were a set of themes that stood out from the 6,989 comments left on the petition: a lack of awareness about perinatal mental illness, the stigma and misunderstanding about maternal mental health and the patchy and insufficient specialist care, as well as the precarious outlook of NHS mental healthcare (RCM, 2017). The conclusion of this research was that maternal mental health care in England is in urgent need of attention. After the petition, the Royal College of Obstetricians and Gynaecologists then performed their own research on 2,200 women (RCOG, 2017). This research showed that there was still a need for a reduction in the stigma of maternal mental health, both within society and within the healthcare services.

For change to begin it has to occur from the grassroots. Midwives are in a 'pivotal position' due to their frequent input during the perinatal period (Sanger et al., 2016) and could provide a more robust and thorough detection of both 
prior and current mental health conditions. This would most usefully occur at the booking-in appointment, and could continue throughout the woman's pregnancy, helping to detect those cases, which at present might be missed or overlooked. Midwives would be in a position to refer women for both preventative care and treatment, within an integrated and family-focused care system at a particularly opportune time when women can most benefit, within the antenatal period, prior to birth. A more robust training that incorporates perinatal mental health at its forefront, in order to increase awareness and knowledge as well as to help reduce stigma within the healthcare services could really enhance the care these women receive and help these women to help themselves, something that most women would want to be able to do. Research is needed to assess the efficacy of enhancing the training of midwives to include a more robust section on perinatal mental health, as well as the benefits to be derived from enhancing the booking-in process and providing midwives with the necessary ability and information to signpost women for suitable treatment.

\section{References}

Agnafors, S., Sydsjö, G., deKeyser, L., Svedin, C.G. (2013). Symptoms of Depression Postpartum and 12 years Later - Associations to Child Mental Health at 12 years of Age. Maternal Child Health Journal, 17, 405-414

Anderson, L., Sundström-Poromaa, I., Bixo, M., Wulff, M., Bondestam, K., Aström, M. (2003). Point prevalence of psychiatric disorders during the second trimester of pregnancy: a populations-based study. American Journal of Obstetrics \& Gynecology, 189, 148-154

Arroll, B., Khin, N., Ngaire, K. (2003) Screening for depressionin primary care with two verbally asked questions: cross sectional study. British Medical Journal, 327,1144 
Australian Government Department of Health and Ageing (2008). National Perinatal Depression Plan

Bauer, A., Knapp, M., Parsonage, M. (2016) Lifetime costs of perinatal anxiety and depression. Journal of Affective Disorders, 192, 83-90

Bonari, L., Pinto, N., Ahn, E., Einarson, A., Steiner, M., Koren, G. (2004). Perinatal risks of untreated depression during pregnancy. Canadian Journal of Psychiatry, 49, 726-735

Britton, J.R. (2008). Maternal anxiety: course and antecedents during the early postpartum period. Depression and Anxiety, 25: 793-800

Buist, A., Bilszta, J., Milgrom, J., Barnett, B., Haynes, B., Austin, M. (2006) Health professional's knowledge and awareness of perinatal depression: results of a national survey. Women and Birth, 19, 11-16

Coble, P.A., Reynolds, C.F., Kupfer, D.J., Houck, P.R., Day, N.L., \& Giles, D.E. (1994). Childbearing in women with and without a history of affective disorder. I. Psychiatric symptomatology. Comprehensive Psychiatry, 35, 205-214.

Cohen, L.S., Altshuler, L.L., Harlow, B.L. (2006) Relapse of major depression during pregnancy in women who maintain or discontinue antidepressant treatment. Journal of the American Medical Association. 295, 499-507

Copper, R.L., Goldenberg, R.L., Das, A., et al (1996). The preterm prediction study: maternal stress is associated with spontaneous preterm birth at less than thirtyfive weeks' getstation. American Journal of Obstetrics and Gynecology, 175, 12861292

Conroy, S., Pariante, C.M., Marks, M., Moran, P.A. (2012), Maternal psychopathology and infant development at 18 months: the impact of maternal personality disorder and depression, Journal of the American Academy of Child and Adolescent Psychiatry 51(1):51-61

Darwin, Z., McGowan, L., Edozien, L.C. (2016) Identifiaction of women at risk of depression in pregnancy: using women's accounts to understand the poor specificity of the Whooley and Arroll case finding question in clinical practice. Archives of Women's Mental Health, 19(1), 41-49

Darwin, Z., McGowan, L., Edozien, L.C., (2014) Antenatal mental health referrals: Review of local clinical practice and pregnant women's experiences in England, Midwifery, 31(3), e17-e22

Deave, T., Heron, J., Evans, J., Emond, A. (2008). The impact of maternal depression in pregnancy on early child development. British Journal of Obstetrics \& Gynecology, 115, 1043-1051

Dennis, C.L., Hodnett, E. (2007). Psychosocial and psychological interventions for 
treating postpartum depression. The Cochrane database of systematic reviews, (4), pp.CD006116

Drewett, R., Blair, P., Emmett, P., Emond, A., the ALSPAC study team (2004) Failure to thrive in the term and preterm infants of mothers depressed in the postnatal period: a population-based birth cohort study. Journal of Child Psychology and Psychiatry, 45(2), 359-366

Faisal-Curry, A., Menzes, P. (2007). Prevalence of anxiety and depression during pregnancy in a private setting sample. Archive of Women's Mental Health, 10, 2532

Field, T., Diego, M., Dieter, J., Hernandez-Reif, M., Schanberg, S., Kuhn, C., Yando, R., (2004). Prenatal depression effects on the fetus and the newborn. Infant Behavior and Development, 27, 216-229

Field, T., Diego, M., Hernandez-Reif, M., Figueiredo, B., Deeds, O., Ascencio, A., Schanberg, S., Kuhn, C., (2010). Comorbid depression and anxiety effects on pregnancy and neonatal outcome. Infant Behavior and Development, 33, 23-29

Fitelson, E., Kim, S., Scott Baker, A., Leight, K. (2011) Treatment of postpartum depression: clinical, psychological and pharmacological options. International Journal of Women's Health, 3, 1-14.

Glover, V. (2014) Maternal depression, anxiety and stress during pregnancy and child outcome; what needs to be done. Best Practice \& Research Clinical Obstetrics and Gynaecology, 28, 25-35

Glover, V., O'Connor, T.G. (2002) Effects of antenatal stress and anxiety. British Journal of Psychiatry, 180, 389-391

Gov.UK (2016) Prime Minister pledges a revolution in mental health treatment Retrieved from https://www.gov.uk/government/news/prime-ministerpledges-a-revolution-in-mental-health-treatment 25th August 2017

Hauck, Y.L., Kelly, G., Dragovic, M., Butt, J., Whittaker, P., Badcock, J.C. (2015) Astralian midwives knowledge, attitude and perceived learning needs around perinatal mental health. Midwifery, 31, 247-255

Hogg, S. (2013) Prevention in Mind. All Babies Count: Spotlight on Perinatal Mental Health. NSPCC, London

Jones, C.J., Creedy, D.K., Gamble, J.A. (2011) Australian midwives attitudes towards care for women with emotional distress. Journal of Midwifery and Women's Health, 56, 353-361

Kaplan, B.J., Leung, B.M., Giesbrecht, G.F., Field, C.j., Bernier, F.P., Tough, S., Cui, X., Dewey, D., and the APrON Study Team (2013). Increasing the quality of life from 
womb to grave: the importance of pregnancy and birth cohorts. Applied Physiology Nutrition and Metabolism, 38, 85-89

Kendell, R.E., Chalmers, J.C., Platz, C. (1987) Epidemiology of puerperal psychoses. British Journal of Psychiatry, 150, 662-673.

Kim, D.R., Sockol, L., Barber, J.P. Moseley, M., Lamprou, L., O’Reardon, J.P., et al. (2011). A survey of patient acceptability of repetitive Transcranial Magnetic Stimulation (TMS) during pregnancy. Journal of Affective Disorders, 129, 385390.

Kingston, D., Tough, S., (2014) Prenatal and Postnatal Maternal Mental Health and School-age Child Development: A systematic review, Maternal and Child Health Journal, 18(7),1728-1741

Knight M, Nair M, Tuffnell D, Kenyon S, Shakespeare J, Brocklehurst P, Kurinczuk JJ (Eds.) on behalf of MBRRACE-UK. Saving Lives, Improving Mothers' Care Surveillance of maternal deaths in the UK 2012-14 and lessons learned to inform maternity care from the UK and Ireland Confidential Enquiries into Maternal Deaths and Morbidity 2009-14. Oxford: National Perinatal Epidemiology Unit, University of Oxford 2016.

Leight, K.L., Fitelson, E.M., Weston, C.A., \& Wisner, K.L. (2010). Childbirth and mental disorders. International Review of Psychiatry, 22(5): 453-471.

Lester, B.M., Conradt, E., Marsit, C.J. (2013). Epigenetic Basis for the Development of Depression in Children. Clinical Obstetrics and Gynecology, Vol 56 , no. $3,556-565$

Lindgren, K. (2001). Relationships among maternal-fetal attachment, prenatal depression, and health practice in pregnancy. Research in Nursing \& Health, 24, 203-217

McCauley, K., Elsom, S., Muir-Cochrane, E., Lyneham, J. (2011) Midwives and assessment of perinatal mental health. Journal of Psychiatric and Mental Health Nursing, 18, 786-795

Milgrom, J., Gemmill, A.W., Bilszta, J.A., Hayes, B., Barnett, B., Brooks, J., Ericksen, J., Ellwood, D., Buist, A. (2008). Antenatal risk factors for postnatal depression: a large prospective study. Journal of Affective Disorders, 108, 147-157

Noonan, M., Doody, O., Jomeen, J., Galvin, R. (2017) Midwives' perceptions and experiences of caring for women who experience perinatal mental health problems: An integrative review. Midwifery, 45, 56-71

O’Hara, M.W., Swain, A.M., (1996). Rates and risk of postpartum depression: a meta-analysis. International Review of Psychiatry, 8, 37-54 
Orr, S.T., James, S.A., Blackmore Prince, C. (2002) Materal prenatal depressive symptoms and spontaneous preterm births among African-American women in Baltimroe, Maryland. American Journal of Epidemiology, 156(9), 797-802

Pearlstein, T.B., Zlotnick, C., Battle, C.L., Stuart, S., O’Hara, M.W., Price, A.B., Grause, M.A., Howard, M. (2006). Patient choice of treatment for postpartum depression: a pilot study. Archives of Women's Mental Health, 9, 303-308

Pearson, R.M., Melotti, R., Heron, J., Joinson, C., Stein, A., Ramchandani, R.G., Evans, J. (2012) Disruption to the development of maternal responsiveness? The impact of prenatal depression on mother-infant interactions

Phillips, L., Thomas, D., (2015) The first antenatal appointment: An exploratory study of the experiences of women with a diagnosis of mental illness, Midwifery, 31(8), 756-764

Rahman, A., Fisher, J., Bower, P., Luchters, S., Tran, T., Yasamy, M.T., Saxena, S., Waheed, W. (2013) Interventions for common perinatal mental disorders in women in low-and middle-income countries: a systematic review and metaanalysis. Bulletin of the World Health Oranization, 91, 593-601

Rahman A, Iqbal Z, Bunn J, Lovel H, Harrington R. Impact of maternal depression on infant nutritional status and illness: a cohort study. Arch Gen Psychiatry 2004; 61: $946-52$

Rahman A, Lovel H, Bunn J, Iqbal Z, Harrington R. (2004) Mothers' mental health and infant growth: a case-control study from Rawalpindi, Pakistan. Child Care Health Dev 2004; 30: 21-7

Rahman, A., Fisher, J., Bower, P., Luchters, S., Tran, T., Yasamy, M.T., Saxena, S., Waheed, W. (2013) Interventions for common perinatal mental disorders in women in low-and middle-income countries: a systematic review and metaanalysis. Bulletin of the World Health Oranization, 91, 593-601

Robertson, E., Celasun, N., and Stewart, D.E. (2003). Risk factors for postpartum depression. In D.E. Stewart, E. Robertson, C.L. Dennis, S.L. Grace \& T. Wallington (pp.12-70). Postpartum depression: Literature review of risk factors and interventions

Ross-Davie, M., Elliot, S., Sarkar, A., Green, L. (2006) A Public Health role in perinatal mental health: are midwives ready? British Journal of Midwifery,14, 330-334

Royal College of Midwives (2017) Every mother must get the help they need. Retrieved from: https://www.rcm.org.uk/sites/default/files/RCM Perinatal\%20Mental\%20Illne ss A4\%20report final.pdf $25^{\text {th }}$ August 2017 
Royal College of Obstetricians and Gynaecologists (2017) Maternal Mental Health - Women's Voices

Rubertsson, C., Hellström, J., Cross, M., Sydsjö, G. (2014). Anxiety in early pregnancy: prevalence and contributing factors. Archives of Women's Mental Health, 17, 221-228

Sanger, C., Haynes, A., Rayns, G., Hogg, S., Galloway, S. (2016) All Babies Count: Reducing the pressure on new families. Midwifery, 31 (3), 345-348

Surkan P, Kennedy C, Hurley K, Black M. Maternal depression and early childhood growth in developing countries: systematic review and meta-analysis. Bulletin Of The World Health Organization [serial online]. August 2011;89(8):607-615D. Available from: Academic Search Premier, Ipswich, MA. Accessed February 7, 2017.

Rahman, A., Iqbal, Z., Bunn, J., Lovel, H., Harrington, R. (2004) Impact of maternal depression on infant nutritional status and illness: a cohort study. Archives of General Psychiartry, 61(9) 946-952

Topiwala, A., Hothi, G., Ebmeier, K.P. (2012) Identifying patients at risk of perinatal mood disorders, The Practitioner, 256(1751) p15-8, 2

Vesga-Lopez, O., Blanco, C., Keyes, K., Olfson, M., Grant, B.F., Hasin, D.S. (2008). Psychiatric disorders in pregnant and postpartum women in the United States. Archive of General Psychiatry, 65, 805-815

Viguera, A.C., Nonacs, R., Cohen, L.S., Tondo, L., Murray, A., Baldessarini, R.J. (2000) Risk of recurrence of bipolar disorder in pregnant and non-pregnant women after discontinuing lithium maintenance. American Journal of Psychiatry, $157,179-184$

Waters, C.S., Hay, D.F., Simmonds, J.R. et al. (2014) Antenatal depression And children's developmental outcomes: potential mechanisms and treatment options. European Child \& Adolescent Psychiatry 23: 957. doi:10.1007/s00787014-0582-3

Whooley, M., Avins, A., Miranda, J., Browner, J. (1997) Case-finding instruments for depression. Two questions are as good as many. Journal of General Internal Medicine, 12 439-445

World Health Organization (2008) Millenium Development Goal 5 - Improving maternal health. World Health Organization: Geneva 